\title{
An Examination of Associated Factors of Emotional Health Problems among Retirees in Kogi State, Nigeria
}

\author{
Veronica J. Ejeh1, Emmanuel E. Achor2, and Esther E Ejeh ${ }^{3}$ \\ 1Department of Physical and Health Education, Kogi State College of Education, Ankpa, Ankpa-Otukpa Rd, Ankpa, Nigeria \\ 2Department of Curriculum \& Teaching, Benue State University, Gboko Road, Walmayo, Makurdi, Nigeria \\ 3Department of Curriculum Studies and Educational Technology, Kogi State College of Education Ankpa, Ankpa-Otukpa Rd, Ankpa, \\ Nigeria
}

\section{*Corresponding Author}

Emmanuel E. Achor

\section{Article History}

Received: 18.09.2019

Accepted: 26.09 .2019

Published: 30.09 .2019

\begin{abstract}
Emotional health problems are common among retirees, but frequently remain undetected and untreated. It occurs in retirement as a result of challenge experienced by retirees, complex interaction of social, psychological and biological factors. The aim of this study is to investigate the associated factors of emotional health problems (depression, anxiety, and stress) among retirees in Kogi State, Nigeria. The study utilized correlational survey research design. The population for the study comprised 9,950 retirees in Kogi State, Nigeria. The retirees aged 60 and above were selected using multi-stage sampling procedure to give a total sample size of 1,250 respondents. The Depression, Anxiety, and Stress Scale (DASS-21) was adapted and used to determine associated factors of depression, anxiety, and stress. Bivariate analyses were performed using frequencies, percentages, point-biserial correlation, Cramer's $V$ coefficient and multiple regression analyses were conducted to determine the relationship between the factors and each of the emotional health problem statuses assessed. The result showed that there were weak positive relationship between depression and age of retirees $\left(r_{p b}=.09, p=.001\right)$, anxiety $\left(r_{p b}=.10, p=.001\right)$, stress $\left(r_{p b}=.14, p=.001\right)$, there were also weak positive relationship between depression and associated factor of income level of retirees and depression $(V=.06, p=.050)$, anxiety $(V=.10, p=.001)$, stress $(\mathrm{V}=.04, \mathrm{p}=.127)$. Furthermore, there were significant relationships between depression and retirees' demographic factors of gender $(P=.000)$ and age $(P=.004)$ and educational level $(p=.000)$ with $5 \%$ of the variation experiences of depression among retirees, Anxiety and retirees' demographic factors of gender $(p=.001)$ and age $(p=.001)$, level of education $(p=.000)$, place of residence $(p=.02)$ and income level $(p=.02)$ with $7 \%$ experiences of anxiety among retirees and stress and retirees' demographic factors of gender $(p=.000)$, age $(p=.000)$, place of residence $(p=.221)$, and educational level $(p=.001)$ with $6 \%$ experiences of stress found among retirees. The study recommended that Kogi State government should establish guidance clinics in all ministries and local government area and pension commissions in the states. This will create opportunities for counselors to provide psychological education to all retiree clients with problems of adjustment. Government should also establish and build a retirement home for the elderly retirees, as well run a social welfare schemes for retirees like we find in developed countries. This will ensure freedom and comfort for smooth transition from the world of work to the world of retirement.
\end{abstract}

Keywords: Retirement; Emotional Health Problems; Age; Gender; depression; anxiety; stress.

\section{INTRODUCTION}

Retirement is a period of fulfillment and actualization after years of meritorious service to the nation. Unfortunately, the thought of retirement to some retirees breeds anxiety, apprehension and disillusionment especially among retirees in Kogi State. Retirement is viewed as a passage that can result in psychological, physiological and economic problems among some retirees [1] The issues of retirement have over the years generated different emotional, psychological and physical problems among retirees because retirement creates fear, stress, depression, despaired, anxiety, uncertainly and feeling of insecurity among retirees. Many scholars such as, Sam, Ogbebor and Enakpoya [2] confirmed that approaching retirement is a source of worry, anxiety and stress for retirees. This could be due to uncertainties in life after retirements. Obimba [3] also discovered that the anxieties of potential retirees are enumerated due to uncertainties of life, financial insecurity, reduced social life and health related problems.

Copyright @ 2019: This is an open-access article distributed under the terms of the Creative Commons Attribution license which permits unrestricted use, distribution, and reproduction in any medium for non commercial use (NonCommercial, or CC-BY-NC) provided the original author and source are credited. 
Retirees, in general, face various challenges that are associated with physical and psychological changes commonly associated with the aging process. WHO [4] attests that emotional health problems constituted the major cause of psychiatric problems, affecting retirees and is associated with increased risk in physical and psychological changes. Although many attributed the changes as normal and acceptable among retirees, there are certain aspects in emotional health that are problem and need to be recognized and treated early, especially those leading to emotional instability [5]. Emotional health problems have become a major public health challenge worldwide. Its threats are enormous psychological, social and economic burden to society and to retirees themselves in both developed and developing nations. It is among one of the burden diseases globally that affect the health conditions and the quality life of retirees. It severely has to a great extent impaired on physical functioning of retirees, and resulted in unnecessary hospitalization or nursing home placement and increased rates of mortality among them. Consequently, many retirees have experienced psychosomatic problems while some exhibit psycho- phobic reactions that lead to unprecedented increase in emotional health problems [6].

Depression affects retirees in Nigeria, because the average income of Nigerian continues to depreciate in value every day, a very peculiar trend in comparison to what is obtained in other parts of the globe. This shows that economic hardship can cause depression, which is in turn among the characteristics of retirement, especially among junior retiring staff [7]. He also states that many retirees became depressed after a major life changes such as death, illness of loved person, retirement, stressful conflicts within the family, sexual or emotional abuse, financial difficulties and violation of one's instructions by other. Depression affects a person's mood, thoughts, feelings, behaviours, and physical health. Severe depression can result in losing the ability to feel pleasure in formerly enjoyable activities and social relationships. Adewuyi [8] states that depression is a persistent low mood which is characterized by sadness, sorrow, loss of pleasure and interest. Surprisingly, retirement in later life has been most consistently linked to increase in depression, as depressed condition of retirees can lead to stress and anxiety.

Anxiety is an unpleasant state of mental uneasiness, nervousness, apprehension and obsession. It is concerned about some uncertainties in life. The implication of anxiety problem entails a group of disorders in which unpleasant feelings of stress, uneasiness, tension, and horror is experienced in confronting a dreaded object or situation, or in resisting obsessions or compulsions; anxiety disturbance is a condition marked by a high level of apprehension and tension, with extreme sensitivity, self-consciousness and morbid fears as in the case of retirement. Ogunbameru and Bamiwuye [1] state that many retirees see work as a source of identification and status, and when is no longer there, they were considered to be ill-dispositions to retirement because of supposed psychological, physiological and financial effects of retirement on retirees. This ill-disposition of retirees in retirement suggests existence of anxiety in them. Therefore, retiree who has not prepared himself to transit and adjust well to it would probably experience anxiety. Idowu and Dada [6] state that retirement by its nature breeds anxiety which involves fears and worries about the future of the individual as a result of cessation in active working life. Sam, Ogbebor and Enakpoya [1] confirmed that retirement is a source of worry, anxiety and stress for retirees.

Stress is an emotional pressure suffered by individual. It is also a physical or psychological demand to which an individual responds. Gaurav [9] defines stress as a state of psychological and physiological imbalance resulting from the disparity between situational demand and the individual's ability and motivation to meet those needs. According to Brehm, Kassin and Fein [10], stress is an unpleasant state of arousal that arises when we perceive that the demands of a situation threaten the ability to cope effectively. The emotional reaction to stress triggers heightened physiological arousal due to increased reactivity of the sympathetic nervous system [11]. Most retirees experience some degree of stress after retirement. It may be stressors emanating from the consequences of the previous working years such as difficulties in assessing one's retirement benefits due to government's beurocracy /corruption, devaluation of benefits due to rising cost of living occasioned by inflation and government corruption or other natural factors not actually related to the work years such as; lack of family support, inability to cater for life's needs, frequent ill-health and cost of coping with same, loneliness, loss of friends and loved ones, low social activities, lost of vigor and strength and general distaste with life. These no doubt are causes and sources of retirement stress to retirees and in no small measures trigger retirement anxiety on those whose retirement are imminent [12]. Mayo Clinic [13] states that common effects of stress on emotional health can cause retirees anxiety, restlessness, lack of motivation or focus, feeling overwhelmed, irritability or anger, sadness or depression, angry outbursts, drug or alcohol abuse, tobacco use and social withdrawal. Stress comes in different dimensions.

It is generally believed that age is one of the determinants of retirement as plays a significant role in determining the level of vulnerability to depression. Age which determines the time of retirement for retirees may also account for differences in their retirement depression, anxiety and stress. APA [14] asserts that older adults continued to report significantly higher levels of depression and anxiety symptoms compared with younger adults. In fact, findings of Ajayi [15] revealed that there were positive relationship between retirement phobia and age. Also at retiree age, they are likely to experience more anxiety about retirement due to its imminence. The disengagement theory [16] which holds that as employees approach retirement age, there is a decrease in emotional involvement in the activities and the social relationships that characterized them as workers, is an indication that age is a factor that accounts for differences in retirees' retirement anxiety. This shows that age is a critical factor in retirees' retirement depression, anxiety and stress. 
The recent global economic recession has promoted increasing concern about the impact of decreasing income as a risk factor for emotional health problems among retirees. Jitender, Traci, Katherine and McMillan [17] Posit that adversity, stress, and reduced capacity to cope is related to low income with the increase in the risk of development of mental illness. Majority of retirees do not work and have fewer options for continued income. Uzoechi and Ubulom [18] observe that apart from financial constraints that can cause depression among retirees, poor social activities and isolation could also lead to depression. They are at risk for rising costs of living, which may place them at an economic disadvantage and potentially at lower levels of Socio-economic status. Olatomide and Akomolafe [19] state that retirement exposes retirees to a sharp reduction in income. Bukoye [20] confirmed that this reduction in income may be aggravated by delay in payment of retirement benefits like pension and gratuity or by inflationary trends. The implication of low income is the practical issues such as this socio-economic disadvantage in early retirement life which may increase vulnerability to depression throughout the lifespan through the effects of poor nutrition, reduced opportunities for education, less access to health care or other mechanisms. Significantly, retirees who still sponsor their children's education at retirement usually face a lot of financial problem as well. Neeta, Karunanidhi and Chitra [21] observe that generally, there is a lowering of income, loss of status, decreased socialization, changes of activity and life style, uncertainty about the future, difficulty in utilization of time and a search for a new identity and status after retirement. The authors further note that retirees who had a high status prior to retirement find the transition difficult due to lower income. A retiree suffers from a loss of prestige along with a loss of income and takes a less productive social and economic role. More than half of Nigerian retirees (58\%) complained bitterly about inadequate pensions or nonpayment of benefits with reported cases of ill-health and untimely deaths [22].

\section{Purpose of the Study}

The purpose of this study was to investigate associated factors of emotional health problems (EHPs) among retirees in Kogi

State, Nigeria. Specifically, the study sought to determine:

- Relationship between gender and EHPs among retirees in Kogi State, Nigeria ;

- Relationship between age and EHPs among retirees in Kogi State, Nigeria;

- Relationship between level of education and EHPs among retirees in Kogi State, Nigeria;

- Relationship between marital status and EHPs among retirees in Kogi State, Nigeria;

- Relationship between income level and EHPs among retirees in Kogi State, Nigeria and

- Find the relationship between place of residence and experience of emotional health problems among retirees in Kogi State?

\section{Research Questions}

The following research questions were answered in this study:

1. What is the relationship between gender and EHPs among retirees in Kogi State, Nigeria

2. What is the relationship between age and EHPs among retirees in Kogi State, Nigeria;

3. What is the relationship between level of education and EHPs among retirees in Kogi State, Nigeria;

4. What is the relationship between marital status and EHPs among retirees in Kogi State, Nigeria;

5. Find out relationship between income level and EHPs among retirees in Kogi State, Nigeria and

6. What is the relationship between place of residence and experience of emotional health problems among retirees in Kogi State?

\section{Hypotheses} freedom.

The following null hypotheses were formulated and tested at .05 of level of significance using appropriate degree of

1. There is no significant relationship between depression and retirees' demographic factors of gender, age, level of education, location, marital status and income level in Kogi State, Nigeria.

2. There is no significant relationship between anxiety and retirees' demographic factors of gender, age, level of education, location, marital status and income level in Kogi State, Nigeria.

3. There is no significant relationship between stress and retirees' demographic factors of gender, age, level of education, location, marital status and income level in Kogi State Nigeria,

\section{Design, Population, Sample and Sampling}

This study adopted correlational research design. The population for the study consists of nine thousand, nine hundred and fifty $(9,950)$ retirees who have retired after 35years of public service or attained 60 years of age from the 21 Local Government Areas of Kogi State [23].

The sample for the study consists of one thousand, two hundred and fifty (1250) retirees in Kogi State. The sample size is determined based on the suggestion of Cohen, Mannion and Morrison [24], which state that when the population size is 10,000 above at $95 \%$ confidence level ( $4 \%$ confidence interval), the sample size should be 566 participants and above. Based on the above, 1250 retirees were considered appropriate as the sample for this study representing $12.5 \%$ of the population. 
The multi- stage sampling procedure was employed in drawing sample for the study. The procedure involved three stages. The first stage involved the use of simple random sampling technique of balloting without replacement to select two (2) senatorial districts (Kogi Central and Kogi East) out of the three (3) senatorial districts/zones in Kogi State. This stage produced two senatorial districts, which were used for the study.

The second stage involved the use of simple random sampling technique of balloting without replacement to select five local Government Areas (5) LGAs each out of the selected two (Kogi Central and Kogi East) senatorial districts in Kogi State. This stage produced a total of ten LGAs, which were used for the study.

In the third stage Convenience sampling was used to select 125 retirees each in the selected 10 LGAs in Kogi State. Paul [25] asserts that Convenience sampling is a non- probability sampling, in which people are sampled simply because they are "convenient" sources of data for researchers. Convenience sampling was used because retirees usually meet once in a month (last Friday of every month). Only retirees who attended such gatherings at designated places were conveniently sampled for the study. This stage produced a total of 1250 retirees used for the study.

\section{Instrument for Data Collection}

The researcher- designed instrument on Emotional Health Problems Questionnaire (EHPSQ) was used to collect data for the study. The EHPSQ contains 68 items classified into six sections namely: A, B, C, D, E, and F. Only sections A to $E$ are relevant to this study. Section A contained items that collected information on personal data of retirees.

Items in sections B to D of the EHPSQ were adopted from standardized instruments. Section B contains the 21 - item: Depression, Anxiety, and Stress scale (DASS-21). The DASS-21 is a set of three self- report scales designed to measure the emotional states of depression, anxiety and stress. The DASS-21 scale was developed by Lovibond and Lovibond [26] with response options of Never (0), Sometimes (1), Often (2), Almost always (3points). Each of the three subscales contains 7 items and divided into subscales with similar content. The depression scale assesses low self-esteem, hopelessness, devaluation of life, self-deprecation, lack of interest or involvement and inertia. The anxiety scale assesses physiological arousal, skeletal muscle effects, situational anxiety, and subjective experience of anxious affect. The stress scale assesses difficulty relaxing, arousal restlessness, nervous arousal, tension, and being easily upset or agitated, irritable or over-reactive and impatient. Scores for depression, anxiety and stress are calculated by summing the scores for the relevant items. A score of 0-4 represents normal state (absence of depression), a score of 5-6 on the depression scale represents "mild depression", 7-10 represents "moderate depression", a score of 11-13 represents "severe depression" while a score of 14 and above (14+) represents extremely severe depression. On the anxiety scale, a score of 0-3 represents normal state (absence of anxiety), a score between 4-5 on the anxiety scale represents "mild anxiety", a score of 6-7 represents "moderate anxiety", 8-9 represents "severe anxiety", while a score of 10 and above (10+) represents extremely severe anxiety. On the Stress scale, scores between the range of 0-7 represents normal stress state (absence of Stress), a score of 8-9 score represents "mild Stress", 10-12 represents "moderate Stress", 13-16 represents "severe Stress" while a score of 17 and above (17+) represents extremely severe Stress.

Section E contains the Clinical Anger Scale (CAS) which was developed by Snell, Gum, Shuck, Mosley and Hite [27]. The CAS is an objective self-report instrument designed to measure the psychological symptoms presumed to have relevance in the understanding and treatment of clinical anger. The CAS contains 21 items and measured based on the CAS items: anger now, anger about the future, anger about failure, anger about things, angry-hostile feelings, annoying others, angry about self, angry misery, wanting to hurt others, shouting at people, irritated now, social interference, decision interference, alienating others, work interference, sleep interference, fatigue, appetite interference, health interference, thinking interference, and sexual interference. Retirees are asked to read each of the 21 groups of statements (4 statements per group) and select the single statement that best describe how they felt (e.g., item 1: $A=I$ do not feel angry, $B=I$ feel angry, $C=I$ am angry most of the time now, and $D=I$ am so angry all the time that I can't stand it). The four statements in each cluster varied in symptom intensity, with more intense clinical anger being associated with statement $D$. Each cluster of statements was scored on a 4-point Likert scale, with $A=0, B=1, C=2$, and $D=3$. The CAS scores are accomplished through the following interpretive ranges: scores between the ranges of 0-13 represent minimal clinical anger, scores within the range of 14-19 represent mild clinical anger, scores of 20-28 represent moderate clinical anger, while scores within the range of 29-63 represent severe clinical anger. Subjects' responses on the CAS are summed so that higher scores correspond to greater clinical anger.

\section{Validity and Reliability of the instrument}

The instrument for data collection was subjected to face validation by five health experts from the Department of Human Kinetics and Health Education, University of Nigeria, Nsukka. Although, the section B to F were adopted from standardized instruments whose psychometric properties have been established by the developers and others authors [26, 27]. The validation become necessary because the environment or location used by the developers was entirely different when compare with the present study. 
The reliability of the instrument (EHPSQ) was established using Cronbach Alpha method of reliability to determine the internal consistency of the instrument. The EHPSQ was administered on 30 retirees in Nsukka Local Government Area Enugu State which is outside the study area. The questionnaire copies were administered to the retirees and collected on the spot. The Depression, Anxiety and Stress Subscale had reliability coefficients of 0.97 . This was considered reliable for the study. According to Cohen et al., [24], when the reliability coefficient of an instrument attains 0.70 and above, the instrument should be considered reliable and suitable enough for a study.

\section{Method of Data Collection}

The distribution and collection of questionnaire took place for the duration of three months. The respondents were contacted in the local government secretariats during retiree's monthly meeting, verification and quarterly meetings. The researcher and her research assistants administered the copies EHPSQ to the illiterate respondents by reading the questionnaire items and interpreting to them in their local languages, and help each of them to attend and complete the questionnaire by ticking the option that best affects them in each of the items based on the responses of the respondents. One thousand two hundred and fifty (1250) copies of questionnaire were administered to the respondents in their respective pension zonal office. Subsequently, the researcher and her assistants collected the completed copies of the questionnaire from the respondents at the spot. For those that could not complete theirs immediately, arrangements were made to collect them at a later date that was agreed by the researcher and the respondents.

\section{RESULTS}

Results are presented according to research questions and hypotheses.

\section{Research Question One}

What is the relationship between age and emotional health problems among retirees in kogi state? Data answering this question are contained in Table-1.

Table-1: Point- Biserial Correlation between Age and Emotional Health Problems among Retirees in Kogi State $(n=1199)$

\begin{tabular}{|l|c|l|}
\hline \multicolumn{3}{|c|}{ Age } \\
\hline EHPs & $\mathbf{r}_{\mathrm{pb}}$ & $\mathrm{p}$ - value \\
\hline Depression & .09 & .001 \\
\hline Anxiety & .10 & .001 \\
\hline Stress & .14 & .000 \\
\hline Anger & .19 & .000 \\
\hline Loneliness & .02 & .500 \\
\hline Cluster value & .11 & .100 \\
\hline
\end{tabular}

Table-1 shows the results of a point-biserial correlation between age and EHPs among retirees. The table shows that there were weak positive relationships between age of retirees and depression $\left(r_{p b}=.09, p=.001\right)$, anxiety $\left(r_{p b}=.10, p=.001\right)$, stress $\left(r_{p b}=.14\right.$, $p=.001)$, anger $\left(r_{p b}=.19, p=.000\right)$ and loneliness $\left(r_{p b}=.02, p=.500\right)$.

\section{Research Question Two}

What is the relationship between gender and emotional health problems among retirees in kogi state? Data answering this question are contained in Table-2.

Table-2: Point - Biserial Correlation between Gender and Emotional Health Problems among Retirees in Kogi State $(\mathrm{n}=$ 1199)

\begin{tabular}{|l|l|l|}
\hline \multicolumn{3}{|c|}{ Gender } \\
\hline EHPs & $\mathbf{r}_{\mathrm{pb}}$ & $\mathrm{p}$-value \\
\hline Depression & .10 & .001 \\
\hline Anxiety & .08 & .003 \\
\hline Stress & .14 & .000 \\
\hline Anger & .16 & .000 \\
\hline Loneliness & .04 & .203 \\
\hline Cluster value & .10 & .040 \\
\hline
\end{tabular}

Source: Nwagu and Agbaje (2017) [28]

Key for interpretation of correlation co-efficient

$\pm .00- \pm .29=$ weak Relationship

$\pm .30- \pm .59=$ moderate Relationship

$\pm .60- \pm .99=$ strong Relationship 
Table-2 shows the result of a point-biserial correlation between gender and EHPs among retirees. The table shows that there were weak positive relationships between gender of retirees and depression $\left(r_{p b}=.10 ; p .001\right)$ anxiety $\left(r_{p b}=.08 ; p .003\right)$, stress $(r p b=.14 ; p .00)$, anger $\left(r_{p b}=.16 ; p .000\right)$, and loneliness $\left(r_{p b}=.04 ; p .203\right)$.

\section{Research Question Three}

What is the relationship between level of education and experience of emotional health problems among retirees in Kogi State? Data answering this question are contained in Table-3.

Table-3: Cramer'sV correlation between Level of Education and Emotional Health Problems among Retirees in Kogi State ( $\mathrm{n}$ = 1199).

\begin{tabular}{|c|c|c|}
\hline \multicolumn{3}{|c|}{ Level of Education } \\
\hline EHPs & $\mathbf{V}$ & $\mathbf{p}$-value \\
\hline Depression & .17 & .000 \\
\hline Anxiety & .20 & .000 \\
\hline Stress & .14 & .000 \\
\hline Anger & .10 & .001 \\
\hline Loneliness & .03 & .334 \\
\hline Cluster value & .13 & .070 \\
\hline
\end{tabular}

Table-3 shows the results of Cramer's V coefficient of correlation between level of education and EHPs among retirees. The table shows that there were weak positive relationships between level of education of retirees and depression $(V=.17, p=.000)$, anxiety $(V=.20, p=.000)$, stress $(V=.14, p=.000)$, anger $(V=.10, p=.001)$ and loneliness $(V=.03, p=.334)$.

\section{Research Question Four}

What is the relationship between income level and experience of emotional health problems among retirees in Kogi State? Data answering this question are contained in Table 4.

Table-4 Cramer's V Correlation between Income Level and Emotional Health Problems among Retirees in Kogi State ( $\mathrm{n}=$ 1199)

\begin{tabular}{|l|l|l|}
\hline \multicolumn{3}{|c|}{ Income Level } \\
\hline EHPs & V & p- value \\
\hline Depression & .06 & .050 \\
\hline Anxiety & .10 & .001 \\
\hline Stress & .04 & .127 \\
\hline Anger & .00 & .982 \\
\hline Loneliness & .01 & .687 \\
\hline Cluster value & .04 & .370 \\
\hline
\end{tabular}

Table- 4 shows the results of a Cramer'sV coefficient of correlation between income level and EHPs among retirees. The table shows that there were weak positive relationship between income level of retirees and depression $(\mathrm{V}=.06, p=.050)$, anxiety $(\mathrm{V}=$ $.10, p=.001)$, stress $(V=.04, p=.127)$, anger $(V=.00, p=.982)$ and loneliness $(V=.01, p=.687)$.

\section{Research Questions Five}

What is the relationship between marital status and experience of emotional health problems among retirees in Kogi State? Data answering this question are contained in Table 5.

Table-5: Cramer'sV Correlation between Marital Status and Emotional Health Problems among Retirees in Kogi State ( $\mathrm{n}=$ 1199)

\begin{tabular}{|c|c|c|}
\hline \multicolumn{3}{|c|}{ Marital Status } \\
\hline EHPs & $\mathbf{V}$ & $\mathbf{p}$ - value \\
\hline Depression & .06 & .030 \\
\hline Anxiety & .08 & .009 \\
\hline Stress & .09 & .002 \\
\hline Anger & .06 & .026 \\
\hline Loneliness & .02 & .593 \\
\hline Cluster value & .06 & .130 \\
\hline
\end{tabular}


Table- 5 shows the results of a Cramer's $V$ coefficient of correlation between marital status and EHPs among retirees. The table shows that there were weak positive relationships between marital status of retirees and depression $(V=.06, p=.030)$, anxiety $(V=.08, p=.009)$, stress $(V=.09, p=.002)$, anger $(V=.06, p=.026)$ and loneliness $(V=.02, p=.593)$.

\section{Research Questions Six}

What the relationship between place of residence and experience of emotional health problems among retirees in Kogi State? Data answering this question are contained in Table 6.

Table 6: Point- Biserial correlation between place of Residence and Emotional Health Problems among Retirees in Kogi State ( $n=1199)$

\begin{tabular}{|l|l|l|}
\hline \multicolumn{3}{|c|}{ Place of Residence } \\
\hline EHPs & $\mathrm{r}_{\mathrm{pb}}$ & $\mathbf{p}$-value \\
\hline Depression & .10 & .001 \\
\hline Anxiety & .13 & .000 \\
\hline Stress & .07 & .014 \\
\hline Anger & .04 & .172 \\
\hline Loneliness & .01 & .619 \\
\hline Cluster value & .07 & .160 \\
\hline
\end{tabular}

Table- 6 shows the results of a point-biserial correlation between place of residence and EHPs among retirees. The table shows that there were weak positive relationship between place of residence of retirees and depression $\left(r_{p b}=.10, p=.001\right)$, anxiety $\left(r_{p b}=.13, p=.000\right)$, stress $\left(r_{p b}=.07, p=.014\right)$, anger $\left(r_{p b}=.04, p=.172\right)$ and loneliness $\left(r_{p b}=.01, p=.619\right)$.

\section{Hypothesis One}

There is no significant relationship between depression and retirees demographic factors of gender, age, location, educational level, marital status and income level. The data verifying this hypothesis are contained in Table-7.

Table-7: Summary of Standard Multiple Regression Analysis for Relationship between Depression and Retirees'

Demographic Characteristics ( $n=1199)$

\begin{tabular}{|l|c|c|c|c|c|l|l|}
\hline Variable & $\mathbf{B}$ & $\mathbf{S E}(\mathbf{B})$ & $\mathbf{B}$ & $\mathbf{T}$ & Sig. & \multicolumn{2}{|c|}{$\mathbf{9 5 \% \text { confidence interval for B }}$} \\
\cline { 7 - 9 } & & & & & & Lower Bound & Upper Bound \\
\hline Gender & 1.116 & .307 & .105 & 3.631 & .000 & .513 & 1.719 \\
\hline Age & -.637 & .220 & -.086 & -2.896 & .004 & -1.068 & -.205 \\
\hline Place of residence & -.614 & .331 & -.057 & -1.852 & .064 & -1.264 & .037 \\
\hline Educational level & .830 & .192 & .140 & 4.320 & .000 & .453 & 1.207 \\
\hline Marital status & .058 & .182 & .010 & .321 & .748 & -.298 & .416 \\
\hline Income level & .265 & .206 & .041 & 1.286 & .199 & -.139 & .668 \\
\hline Constant & 7.096 & 1.238 & ------- & 5.734 & .000 & 4.667 & 9.524 \\
\hline
\end{tabular}

Note: $R=.22, R^{2}=.049, \operatorname{Adj} . R^{2}=.044, F(6,1192)=10.152$

$\mathrm{R}=$ Pearson's correlation coefficient

$R^{2}=$ Coefficient of determination

Adj. $R^{2}=$ Adjusted $R$ square

$B=$ Unstandardized coefficients

SE $(B)=$ Standard error for unstandard

$\beta=$ Standard coefficients Beta

$\mathrm{t}=\mathrm{t}$-test value

sig. = significance level (Alpha level)

${ }^{*} \mathrm{P}<.05$

Results in Table-7 show the standard multiple regression conducted to examine the relationship between depression and demographic characteristics of retirees. The results showed that there was a weak positive relationship between depression and demographic characteristics of retirees in Kogi State $(R=.22)$. The standard multiple regression results showed that there were significant relationships between depression and gender $(P=.000)$, depression and age $(P=.004)$, depression and educational level $(p$ $=.000$ ) among retirees. The $R^{2}$ value of .049 implies that the entire model explained only $4.9 \%$ of the variation in the experience of depression among retirees. However, in the model, place of residence $(P=.064)$, marital status $(p=.75)$ and income $(p=.20)$ of retirees did not significantly determine depression among retirees in Kogi State. 


\section{Hypothesis eight}

There is no significant relationship between anxiety and retirees demographic factors of gender, age, location, educational level, marital status and income level. The data verifying this hypothesis are contained in Table-8.

Table-8: Summary of Standard Multiple Regression Analysis for Relationship between Anxiety and Retirees' Demographic Characteristics $(n=1199)$

\begin{tabular}{|l|l|l|l|l|l|l|l|}
\hline Variable & $\mathbf{B}$ & SE(B) & $\mathbf{B}$ & $\mathbf{T}$ & Sig. & \multicolumn{2}{|c|}{$\mathbf{9 5 . 0 \%}$ confidence interval for B } \\
\cline { 7 - 9 } & & & & & & Lower Bound & Upper bound \\
\hline Gender & 1.104 & .317 & .100 & 3.481 & .001 & .482 & 1.722 \\
\hline Age & -.771 & .227 & -.100 & -3.398 & .001 & -1.216 & -.326 \\
\hline Place of residence & -.832 & .342 & -.074 & -2.433 & .015 & -1.503 & -.161 \\
\hline Educational level & .995 & .198 & .161 & 5.018 & .000 & .606 & 1.385 \\
\hline Marital status & .086 & .188 & .014 & .461 & .645 & -.282 & .455 \\
\hline Income level & .508 & .212 & .075 & 2.391 & .017 & .091 & .924 \\
\hline Constant & 7.394 & 1.277 & ------ & 5.790 & .000 & 4.889 & 9.900 \\
\hline
\end{tabular}

Note: $R=.26, R^{2}=.067$, Adj. $R^{2}=.062, F(6,1192)=14.208$

Result in Table-8 show the result of the standard multiple regressions conducted to examine the relationship between anxiety and demographic characteristics of retirees. The results showed that there was a weak positive relationship between anxiety and characteristics of retirees in Kogi State $(R=.26)$. They were significant relationships between anxiety and gender $(\mathrm{p}=.001)$, anxiety and age $(p=.001)$, anxiety and level of education $(p=.000)$, anxiety and place of residence $(p=.02)$ and anxiety and income level $(p=.02)$ among retirees. The $R^{2}$ value of .067 implies that the entire model explained only $6.7 \%$ of the variation in the experience of anxiety among retirees. However, in the model of marital status $(p=.65)$ did not significantly determine anxiety among retirees in Kogi State.

\section{Hypothesis Three}

There is no significant relationship between stress and retirees demographic factors of gender, age, location, educational level, marital status and income level. The data verifying this hypothesis are contained in Table-9.

Table 9: Summary of Standard Multiple Regression Analysis for Relationship between stress and retirees' Demographic Characteristics $(n=1199)$

\begin{tabular}{|c|c|c|c|c|c|c|c|}
\hline \multirow[t]{2}{*}{ Variable } & \multirow[t]{2}{*}{ B } & \multirow[t]{2}{*}{$\mathrm{SE}(\mathrm{B})$} & \multirow[t]{2}{*}{ B } & \multirow[t]{2}{*}{$t$} & \multirow[t]{2}{*}{ Sig. } & \multicolumn{2}{|c|}{$95 \%$ confidence interval for B } \\
\hline & & & & & & Lower Bound & Upper bound \\
\hline Gender & 1.409 & .281 & .144 & 5.009 & .000 & .857 & 1.961 \\
\hline Age & -.847 & .201 & -.125 & -4.210 & .000 & -1.242 & -.452 \\
\hline Place of residence & -.372 & .303 & -.037 & -1.225 & .221 & -.967 & .223 \\
\hline Educational level & .602 & .176 & .110 & 3.421 & .001 & .257 & .947 \\
\hline Marital status & -.124 & .166 & -.022 & -.743 & .458 & -.450 & .203 \\
\hline Income level & .319 & .188 & .053 & 1.693 & .091 & .051 & .688 \\
\hline Constant & 6.547 & 1.132 & 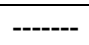 & 5.782 & .000 & 4.326 & 8.769 \\
\hline
\end{tabular}

Results in Table-9 show the results of standard multiple regression conducted to examine the relationship between stress and demographic characteristics of retirees. The results showed that there was a weak positive relationship between stress and demographic characteristics of retirees in Kogi State $(R=.25)$. There were significant relationships between stress and gender $(p=.000)$, stress and age ( $p=.000)$, and stress and educational level $(p=.001)$ among retirees. The $R$ value of .060 implies that the entire model explained only $6 \%$ of the variation in the stress experienced by retirees. However, in the model, marital status $(p=.46)$ and income level $(p=.091)$ of retirees did not significantly determine stress among retirees in Kogi State.

\section{Discussion}

It is found that there were weak positive relationships between age and depression, anxiety, stress, anger and loneliness. This means that age has weak positive relative value not high on emotional health problems among retirees in Kogi State. It implies that those retirees at 60 to 79 years and those at 80years and above experience various form of emotional health problems at a weak related value despite their age bracket. This finding is not expected but surprising because the prevalence of emotional health problems is high among the elderly retired, with a prevalence of almost $20 \%$ in people aged 65 years and older. This result is not in line with the report of WHO [29] which stated that Over $20 \%$ of retiree adults aged 60 and over suffer from a emotional or neurological problem. Sarah [30] also agreed with the statement that $20 \%$ of adults aged $55-65$ experiences some type of emotional health problems. The implication is that the retirees are vulnerable to emotional health problems despite their age bracket. They should be 
guided and protected against conditions that lead to serious emotional health problems by families and government no matter their age rage.

It is found that there were weak positive relationship between income level of retirees and depression, anxiety, stress, anger and loneliness. This finding is not expected because income level influences retiree's ability to adjust effectively in their emotional status. Monetary resources entails coping options in nearly all stressful situations, providing easier and probably more effective access to legal, medical and other assistance in retirement life. Even when money is not spent directly on managing the problem, financial security can reduce the impact of stress, depression, anxiety etc. This finding is not in agreement with the findings of Kim and Moen [31], who found that inadequate incomes and financial problems predict emotional dissatisfaction and maladjustment to retirees. The finding did not tally with Bola and Lai [22] study which stated that more than half of Nigerian retirees (58\%) complained bitterly about inadequate pensions or non-payment of benefits with reported cases of ill-health, emotional problems and untimely deaths. This is also not in line with the findings of Muramatsu, Hoyem, Yin, and Campbell [32] which shown that lack of financial resources relates negatively with emotional health adjustment in terms of retirement satisfaction and well-being. The implication on this finding is that income levels can influences the emotional status of retirees either negatively or positively because money is needed by the retirees directly in managing problem, as financial security to reduce the impact of emotional health problems. Government and employer should ensure proper counseling service to enhanced better financial situation of retirees as preventive strategies of emotional health problems.

Another finding is that there was significant relationship between depression and demographic factors of gender, age and educational level among retirees in Kogi State. This implies that gender, age, and educational level are associated with depression among retirees in Kogi State. This finding is expected not surprising because depression affects lot of retirees ages 65 and older, due to injury or illness, suffering from loss of job, or situational challenges which lead to somatic complaints that are bodily manifestations of depression. This finding is in conformity with the study of Aaqib and Sarah [33] who asserted that among socio- demographic factors gender, low socioeconomic status, educational level are found to have significant role in trigging depression in later-age (retired). The obvious implication is that depression ascertained as prevalent emotional problems. Intervention step is needed to avert the impair of depression on retiree's ability to function and enjoy life, which contribute to poorer overall emotional health

One of the findings of this study is that there was significant relationship between anxiety and demographic factors of gender, age, level of education, place of residence and income level among retirees in Kogi State. This finding is expected because anxiety is a condition marked by a high level of apprehension and tension, with extreme sensitivity, self-consciousness and morbid fears as in the case of retirement anxiety which is usually associated with unpreparedness and insecurity about the retirees future especially when related to the uncertainties of life, apprehensive in approaching the future, in facing lots of problems among other things like reduction in their income. This finding agreed with the findings of Vink, Aertsen and Schoevers [34] who stated that age, gender, and lower income, and a number of mental illnesses are associated with late-life anxiety. The finding is consistent with the finding of Crystal [35] who stated that Anxiety problems affect 3-14\% of retirees older than 65 years and more than $27 \%$ of retired adults reported having symptoms of anxiety. The implication of this finding is that gender, age, educational level, place of resident and income level are determinant for anxiety among retirees. It implies that anxiety of potential retirees should be equipped with the identified strategies of seeking pre-retirement counselling from professionals, having a sense of self-reliance and making appropriate savings and investment before retiring amongst others that will go a long way in curbing retirement anxiety in retirees.

It is also found that were there was significant relationships between stress and retirees' demographic factors of gender, age, place of residence and educational level among retirees in Kogi State. This finding is expected because retirees experience stresses associated with financial difficulties and depression. The finding is in line with the finding Gardener [36] affirmed that retiree generally experience higher levels of stress and this contributed to higher depression than their counterpart with lower level of stress and that of the general population. The finding is supported with the study conducted by Morrison and O'Connor [37] who stated that stress is a predictor of depression among retirees and that depression has grave consequences for retirees as well as the wider community. The implication of the finding is that stress state is determined by gender, age, place of resident and educational level among retirees. Stress is a serious emotional problem that needs attention to avoid complication. It implies that stress management programme should be adopted to address the diverse needs of retirees.

\section{CONCLUSIONS}

Based on the findings and discussion, the following conclusions were reached:

- $\quad$ There was a weak positive relationship between age and emotional health problems among retirees.

- $\quad$ There was a weak positive relationship between income level and emotional health problems among retirees.

- There were significant relationships between depression and gender, depression and age and depression and level of education among retirees.

- There were significant relationships between anxiety and gender, anxiety and age, anxiety and level of education, anxiety and place of residence and anxiety and income level among retirees. 
- There were significant relationships between stress and gender, stress and age, and stress and level of education among retirees.

\section{RECOMMENDATIONS}

Based on the findings of the study, the following recommendations were made:

- Efforts should be intensified to organize programmes that aimed at helping retirees adjust to a non-working lifestyle not minding their gender differences, it should be offered especially for potential voluntary retirees to enable them maintained a positive emotional health conditions. In order to avoid emotional health problems like depression, anxiety, stress, anger, loneliness etc.

- Kogi State government should establish guidance clinics in all ministries and local government area and pension commissions in the states. This could create opportunities for counselors to provide psychological education to all retiree clients with problems of adjustment.

- Government should establish and build a retirement home for the elderly retired, as well as running a social welfare schemes for retirees, like we find in developed countries. This will ensure smooth transition from the world of work to the world of retirement,

\section{REFERENCES}

1. Ogunbameru, O., \& Bamiwuye, T. (2004). Attitudes towards retirement and pre-retirement education among Nigerian bank workers. Educational Gerontology, 30(5) 391-401.

2. Sam, D. O. C., Ogbebor, G. G., \& Enakpoya, E. E. (2010). Retirement anxiety and counselling needs of pre-retirees in Delta state. The counsellor, 27, 76-82.

3. Obimba, F. V. (2005). Anxiety over the uncertainties of life in retirement: Implication for counseling. The counselor, 16(1) 184193.

4. World Health Organization (2001). Strengthening Mental Health Promotion. Geneva.

5. Blazer, D. G., \& Hybels, C. F. (2005). The association of depression and mortality in elderly persons: a case for multiple, independent pathways. Journals of Gerontology Series A, Biological Sciences and Medical Sciences, 56(8), M505-9.

6. Dada, M. F., \& Idowu, A. (2007). Counselling Strategies for Managing Pre-Retirement Anxiety among Employees. Ilorin Journal of Education. www.unilorin.edu.ng/.../couselling \%20\%strategies\%20For\%20Managing\%Pre-Retirement

7. Mohammed, A. I. (2007). Cause and implications of depression in adults: A challenge to psychologist in Nigeria. A paper presented at $7^{\text {th }}$ national conference of Nigeria society for educational psychologist (NISEP) Jos.

8. $\quad$ Adewuyi, T. D. O. (2008). Plan for your retirement now. Lagos: Acts system publisher.

9. Gaurav, A. (2011). What is Stress? Meaning, Definition and Causes of Stress. Post Comment (1). Label Industrial Psychology.

10. Brehm, S. S., Kassin, S. M., \& Fein, S. (2002). Undergraduate psychology major learning goals and outcomes: A report.

11. Ifeagwazi, C. M., Chukwuorji, J. C., \& Kalu, O. G. (2013). Role of stress reactivity, age and gender on neuroticism among students. International Journal of Research in Arts and Social Sciences, (5), 521-530.

12. Baba, M. M., Garba, H. K., \& Zakariyah, A. A. (2015). Pre-retirement anxiety among Nigerian public servants: Counseling Intervention Strategies for Mitigating Effects for Self-Reliance and National Development. Journal of Sociology, Psychology and Anthropology in Practice, 7(2), 23-32.

13. Mayo Clinic (2017). Mayo Foundation for Medical Education and Research (MFMER).

14. Australian Psychology Society. (2014). Stress and wellbeing in Australia survey. psychology.org.au/npw.

15. Ajayi, M. A. (2007). Perceived retirement phobia as a function of age, educational and marital status of professional soccer players. Journal of Finance and Economics, 10(9), 57-64. York. McGraw-Hill.

16. Cumming, E., \& Henry, W. E. (1961). The process of disengagement. New York: Basic Books.

17. Jitender, S., Tracie, O. A., Katherine, A., \& McMillan, M. S. (2011). Relationship between Household Income and Mental Disorders: Findings from a Population-Based Longitudinal Study. Arch Gen Psychiatry, 68(4):419-427.

18. Uzoechi, K. C., \& Ubulom, W. J. (2001). Sources of depression among civil servant retirees in Ideato-north local government area of Imo state: Implications for counselling. African Journal of Interdisciplinary Studies, 2(1 \& 2).

19. Olatomide, O. O., \& Akomolafe, M. J. (2012). Assessment of pre-retirement guidance needs of near-retirement teachers in public primary schools in two Local Government Areas in Ondo State, Nigeria. Ife Journal of Educational Leadership, Administration and Planning.

20. Bukoye, R. O. (2005). Problems associated with retirement anxiety among retiring civil servants in Kwara State. The Counsellor, (21), 207-215.

21. Neeta-Sharma, K. L., Karunanidhi, S. L., \& Chitra, T. (2015). Determinants of psychological well-being among retirees. International Research Journal of Social Sciences, 4(3), 19-26.

22. Bola, A., \& Lai, O (2014). Gender differentials in retirement antecedents and life satisfaction of formal sector retirees in Lagos State, Nigeria. The Journal of Aging in Emerging Economies, 2, 11-19.

23. Bureau for Local Government Pension. (2017). Kogi State Government, Nigeria. Lokoja: Govt. Press.

24. Cohen, L., Mannion, L., \& Morrison, K. (2011). Research method in education ( $7^{\text {th }}$ edition). New York. Rout ledge Taylor and Francis Group. 
25. Paul, J. L. (2008). Convenience Sampling. Encyclopedia of Survey Research Methods.

26. Lovibond, S. H., \& Lovibond, P. F. (1995). Manual for the depression anxiety \& stress scales. (2 Ed.)Sydney: Psychology Foundation.

27. Snell, W. E., Jr., Gum, S., Shuck, R. L., Mosley, J. A., \& Hite, T. L. (2013). The Clinical Anger Scale (CAS). Measurement Instrument Database for the Social Science. Retrieved from www.midss.ie

28. Omoshaba, E. O., Olufemi, F. O., Ojo, O. E., Sonibare, A. O., \& Agbaje, M. (2017). Multidrug-resistant Salmonellae isolated in Japanese quails reared in Abeokuta, Nigeria. Tropical animal health and production, 49(7), 1455-1460.

29. World Health Organization. (2017). The determinants of health. Health Impact Assessment. Retrieved from www.who,int/ hia/evdidence/doh/en.

30. Sarah, S. (2018). 10 Symtoms of mental illness in the elderly. Senior living Blog. http://www.aplaceformom.com>blog.

31. Kim, J. E., \& Moen, P. (2002). Retirement transitions, gender and psychological well-being: A Life-course ecological model. Journal of Gerontology: Psychological Science, 57(3) 212-222.

32. Muramatsu, N, Hoyem, R. L, Yin, H., \& Campbell, R. T, (2008). Place of death among older Americans: Does state spending on home- and community-based services promote home death? Medical Care, 46(8):829-838.

33. Aaquib, S. A., \& Sarah, S. (2017). Depression and risk factors among elderly population of Central Punjab, Pakistan. Rawal Medical Journal, 4(42), 571-574.

34. Vink, D., Aartsen, M. J., \& Schoevers, R. A. (2008). Risk factors for anxiety and depression in the Elderly: A Review. Journal Affect Discords, 106, 29-44.

35. Crystal, J (2018). 3 Strategies for dealing with anxiety in Seniors. Seniors living blog. http:www.a place for mom

36. Gardener, S. (2010). Stress among prospective teachers: A review of the literature. Australian Journal of Teacher Education, $35(8), 18-28$.

37. Morison, R., \& O'Connor, R. C. (2005). Predicting psychological distress in college students: .The role of rumination and stress. Journal of Clinical Psychology, 61(4), 447-460. 